\title{
Effect of Boron Concentration on Dynamic Recrystallization Behavior of Low-Carbon Steel
}

\author{
Yong-Liang Gao ${ }^{1} \cdot$ Xiang-Xin Xue ${ }^{1} \cdot$ He Yang $^{1}$
}

Received: 26 January 2015/Revised: 25 March 2015/Published online: 6 May 2015

(C) The Chinese Society for Metals and Springer-Verlag Berlin Heidelberg 2015

\begin{abstract}
The dynamic recrystallization behavior of low-carbon steel containing three different amounts of boron ( 0.002 , 0.004 , and $0.006 \mathrm{wt} \%$ ) was systematically investigated under various experimental conditions. Low-carbon steel was exposed to temperatures ranging from 900 to $1100{ }^{\circ} \mathrm{C}$, strain rates from 0.1 to $10 \mathrm{~s}^{-1}$, and inspection of the initial austenite grain size at $1150{ }^{\circ} \mathrm{C}$. The resulting stress-strain curves are observed to possess two classifications of behavior, dynamic recovery and dynamic recrystallization, while the initial austenite grain size increases directly proportional to boron concentration. Additionally, the characteristic points of the flow curves were analyzed by regression method in which the peak and critical stresses decreased in response to an increase in boron composition, indicating that a softening effect appears with the addition of boron. On the contrary, peak and critical strains increased as boron content increased, indicating that boron has the ability to delay the onset of dynamic recrystallization. Lastly, the kinetics model of dynamic recrystallization for three boron-treated steels was established.
\end{abstract}

KEY WORDS: Boron-treated steel; Hot deformation; Flow stress; Dynamic recrystallization

\section{Introduction}

In recent years, the demand to fully comprehend high-temperature deformation behavior of metallic metals is coming to the forefront of the metallurgical industry [1,2]. Various phenomena have been shown to occur during the high-temperature deformation process of austenitic steel: (1) work hardening, (2) dynamic recovery (DRV), and (3) dynamic recrystallization (DRX) depending on tunable process conditions such as deformation temperature and strain rate. DRX occurs in materials with low stacking fault energies and when sufficient

Available online at http://link.springer.com/journal/40195

Xiang-Xin Xue

xuexx@mail.neu.edu.cn

1 Liaoning Key Laboratories of Ecological Utilization Technology of Boron Resources and Boron Materials, Northeastern University, Shenyang 110819, China suppression of the restoration process occurs during deformation. Subsequently, strain accumulates up to a critical value where dislocation density is sufficient enough for grain nucleation [3-5]. Once DRX finishes, significant refinement of the austenitic microstructure and a fine final ferrite grain size is observed [6]. Both the strength and the ductility of the material increase by refining grain morphology. Therefore, DRX is a dominant factor in controlling the steel microstructure evolution and performance during high-temperature deformation.

Since the discovery of boron's effect on the hardenability of low-carbon steel, boron-treated steel has been applied in numerous applications of structural materials, wear-resistance steels, high tensile strength steels for weld structure, and costeffective steels in which a small amount of boron can replace expensive, alloying elements such as $\mathrm{Ni}, \mathrm{Cr}$, and $\mathrm{Mo}$ [7-9]. Advantageously, hardenability occurs because boron atoms easily segregate to prior austenite grain boundaries, lowering the grain boundary energy while retarding the transformation of austenite to ferrite. Generally speaking, grain boundary 
Table 1 Chemical composition of the test steels (wt \%)

\begin{tabular}{llllllllll}
\hline Steels & C & Si & Mn & S & P & Al & B & N & Fe \\
\hline B1 & 0.18 & 0.184 & 0.619 & 0.025 & 0.016 & 0.051 & 0.002 & 0.004 & Bal. \\
B2 & 0.18 & 0.191 & 0.626 & 0.025 & 0.016 & 0.049 & 0.004 & 0.004 & Bal. \\
B3 & 0.18 & 0.196 & 0.626 & 0.025 & 0.016 & 0.049 & 0.006 & 0.004 & Bal. \\
\hline
\end{tabular}

segregation of boron in steel occurs via two mechanisms of equilibrium and non-equilibrium segregation [10]. Equilibrium grain boundary segregation occurs by the migration of solute atoms from the grain matrix interior to loosely packed regions (i.e., grain boundaries), thus reducing grain boundary free energy. Non-equilibrium grain boundary segregation has been observed during the cooling process from high temperatures due to the diffusion of vacancy-solute complexes toward grain boundaries. Qualitatively, non-equilibrium segregation proves to be the dominant contributing factor in conventional heat treatment conditions of steel [11]. Migration of boron to the austenite grain boundaries affects the thermodynamics of the respective boundaries, which critically effects the softening behavior of austenite during hot working [12]. However, the effect of boron on hot flow behavior is still disputed by numerous authors. Mejía et al. [13] and Chipres et al. [14] have reported that boron addition generates a softening effect and accelerates the onset of DRX. Related works [15-17] also found boron to facilitate the DRX process. However, Kim et al. [18], Banks et al. [19], and Stumpf et al. [20] observed boron having a delayed effect of the onset and rate of DRX. Although many investigations [2123 ] report the initial austenite grain size effects on the DRX behavior, few reports, to the best of our knowledge, demonstrate the effect of boron on initial austenite grain size.

The majority of previous works [21-23] have investigated the kinds of boron steel with alloy elements such as $\mathrm{V}, \mathrm{Ti}, \mathrm{Nb}$, $\mathrm{Cr}, \mathrm{Cu}$, and $\mathrm{Mo}$; thus, microstructure, such as initial austenite grain size, and dislocation mobility are varied by these alloy elements. In fact, initial austenite grain size has demonstrated strong effects on the DRX behavior. To date, the effects of boron content on DRX kinetics have not been systematically quantified for situations where boron is the sole additive. The aim of this research work is to study the effects of boron addition on the hot flow behavior in low-carbon steel. The flow curves at different deformation and critical parameters as a function of boron composition are presented. Initial austenite grain sizes at different boron loadings are discussed as well as the kinetics models of DRX for three boron steel samples.

\section{Experimental}

Low-carbon boron-treated steels were fabricated via vacuum induction melting, and the ingots were hot rolled into a 12-mm-thickness plate followed by air cooling. The chemical compositions of the three steels are listed in Table 1. Cylindrical specimens $15 \mathrm{~mm}$ in high and $8 \mathrm{~mm}$ in diameter were machined from the plate, and Gleeble-2000 thermo-mechanical simulator was used for compression testing and heat treatment. For compression testing, the samples were heat to $1150{ }^{\circ} \mathrm{C}$ at a rate of $10{ }^{\circ} \mathrm{C} / \mathrm{s}$ and held for $180 \mathrm{~s}$ for austenitizing. Subsequently, samples were cooled to the deformation temperature at $10{ }^{\circ} \mathrm{C} / \mathrm{s}$ and maintained for $30 \mathrm{~s}$. Five different deformation temperatures (900, 950, 1000, 1050 , and $\left.1100{ }^{\circ} \mathrm{C}\right)$ and three strain rates $\left(0.1,1\right.$, and $\left.10 \mathrm{~s}^{-1}\right)$ were used in hot compression tests, and the true strain achieved was 0.8 . In order to study the effect of boron content on initial austenite grain size, specimens were heated to $1150{ }^{\circ} \mathrm{C}$ and isothermally maintained for $5 \mathrm{~min}$ and subsequently quenched in water.

Generally, it is arduous to determine the critical point of DRX based on the plot of stress versus strain; however, the most accepted method described by Poliak and Jonas $[24,25]$ focuses on changes in the strain hardening rate as a function of the flow stress. The plot of strain hardening rate $(\theta=\mathrm{d} \sigma / \mathrm{d} \varepsilon)$ versus true stress $(\sigma)$ has its advantages in describing the critical point of DRX, revealing the changes in microstructure of inspected materials from the deformation process. In the $\theta-\sigma$ plot, the points where the plot crosses the zero from above represent the peak stress while the initiation of DRX appears as a distinct minimum in the $-(\mathrm{d} \theta / \mathrm{d} \sigma)-\sigma$ plot. The microstructure of prior austenite was observed by using optical microscope (LEICA DM 6000) after being corroded in saturated picric acid solution. The austenite grains choosing six visual fields in every specimen were observed on optical microscope. Each visual field was measured by the linear intercept method through image software, counting the number of grains intercepted by straight lines long enough to yield at least 50 intercepts in total, ensuring accuracy, while utilizing the mean chord length of austenite grain as a measure of its grain size.

\section{Results and Discussion}

\subsection{Flow Stress}

The flow stress curves of boron-treated steels deformed at distinct temperatures and strain rates are shown in Fig. 1. It can be seen that the deformation temperatures and strain 

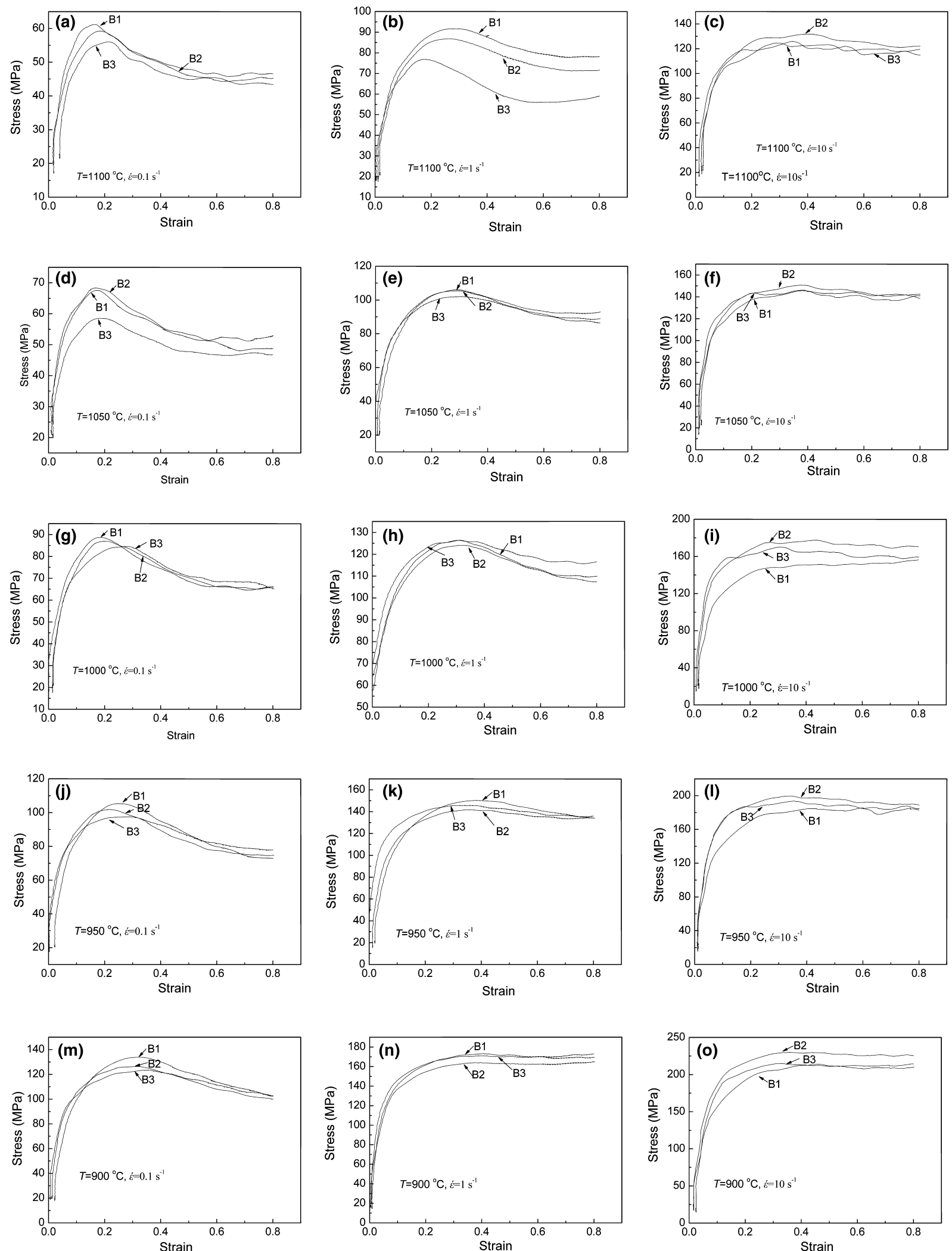

Fig. 1 Stress-strain curves as a function of boron content (B1, B2, and B3) at different temperatures $\left(900,950,1000,1050\right.$, and $\left.1100{ }^{\circ} \mathrm{C}\right)$ and strain rates $\left(0.1,1\right.$, and $\left.10 \mathrm{~s}^{-1}\right)$ 
rates have considerable influence on the hot deformation behavior of the steel samples. The flow stress of each steel decreases significantly as temperature increases and strain rate decreases. Furthermore, the stress-strain curves (Fig. 1) demonstrate a distinct classification of mechanisms taking place, DRV and DRX. DRV occurs for all deformation temperatures at a strain rate of $10 \mathrm{~s}^{-1}$. When the strain rate decreases to $1 \mathrm{~s}^{-1}$, DRV is only observed to occur at a deformation temperature of $900{ }^{\circ} \mathrm{C}$. The trends of curves in Fig. 1 exhibit standard DRX behavior under lower strain rates $\left(0.1\right.$ and $\left.1 \mathrm{~s}^{-1}\right)$. In addition, the DRX plots demonstrate steel containing a higher boron concentration yielding a lower peak stress value compared with a sample with less boron at an identical temperature and strain rate. Accordingly, it is believed that boron has a solid solution softening effect, identical to the role played by other interstitial elements such as carbon. The softening effect exhibited by carbon increases its self-diffusivity and decreases its Young's modulus, while the diffusion rate of boron in austenite mimics carbon [26, 27]. To explain this phenomenon, various theories about solid solution softening effect of boron were developed. For example, the work of Jahazi and Jonas [28] demonstrates boron possessing dual behavior in the austenite lattice, i.e., boron occupying substitutional and interstitial sites, and diffusion will be accelerated by boron from its substitutional position to its interstitial one under sufficient energy conditions. The softening mechanism can also occur via an additional channel of facilitated formation of dislocation kinks at impurity centers (decrease kink energy and facilitate dislocation mobility) [29, 30]. Previously mentioned phenomena has also been explained on the basis of the non-equilibrium segregation, as an effect of mobile vacancy-solute atom complexes diffusing through a vacancy gradient toward vacancy sinks (this gradient can be generated via plastic deformation). In this case, the grain boundary softening is most likely due to the presence of solute clusters resulting from the decomposition of vacancy-solute complexes near the boundary sink [31].

In DRV process, the curve increases to a peak and reaches steady state conditions without any downfall, as shown in Fig. 1c, f, i, j, and o. Generally, this is ascribed to the higher strain rate that provides shorter time for energy accumulation and lower mobility at the boundary; these phenomena result in nucleation and growth of dynamically recrystallized grains while also creating dislocation annihilation [32-34]. In addition, Fig. 1 displays B2 samples possessing an increased flow resistance in relation to the B3 samples, which only show a higher flow resistance relative to $\mathrm{B} 1$ samples at high strain rate $\left(10 \mathrm{~s}^{-1}\right)$. It can be seen that the effect of boron in steels at low strain rate
(DRX) behaves opposite in its trend compared with steel at a high strain rate (DRV). The expressed data proves to be identical with the results reported by Kim et al. [18]. Reasoning for this phenomenon is that boron atoms have insufficient time for reorganization that allows them to have no significant effect on softening under high strain rate. Additionally, results exhibit boron atoms hindering dislocation motion at high strain rates, and pinning effect decreases when boron reaches a distinct concentration limit.

\subsection{Characteristic Points of Flow Stress Plot}

The trend of hardening rate $(\theta=\mathrm{d} \sigma / \mathrm{d} \varepsilon)$ and true stress $(\sigma)$ accurately determines the characteristic value of the flow plot, commonly used to determine peak stress $\left(\sigma_{\mathrm{p}}\right)$, the critical stress corresponding to the critical strain $\left(\varepsilon_{\mathrm{c}}\right)$, the saturated stress $\left(\sigma_{\mathrm{sat}}\right)$, and the steady stress $\left(\sigma_{\mathrm{ss}}\right)$. It is well understood that the curve of $\theta-\sigma$ (Fig. 2a) can be divided into four phases: (1) Stage I is a straight line segment and the value of $\theta$ decreases sharply, showing formation of subgrain in the material; (2) stage II shows the slope of the curve decreases as the DRV rate diminishes; (3) stage III indicates the deformation stage from the onset of DRX to the intersection of stress $(\theta=0)$, or the peak stress; and (4) stage IV demonstrates complete DRX. Figure $2 b, c$ and $d$ shows $\theta-\sigma$ plots for B1, B2, and B3 steels at $0.1 \mathrm{~s}^{-1}$ and different deformation temperatures. In this case, it can be clearly observed that the peak stress of all steels increases with decreasing temperature. According to this method, the peak stress can be precisely measured as $61.43,65.75$, 88.07, 106.53, and 134.52 MPa for steel B1 and 55.73, 57.12, 85.32, 97.74, and 123.07 MPa for steel B3 at 1100, $1050,1000,950$, and $900{ }^{\circ} \mathrm{C}$, respectively.

Even though $\theta-\sigma$ plots show the point of critical stress, they do not provide precise information about the onset of DRX. However, the inflection point, appearing as a distinct minimum in the $-(\mathrm{d} \theta / \mathrm{d} \sigma)-\sigma$ plot, represents the initiation of DRX mechanism. Based on the analysis above, a precise value of critical stress is determined by investigating the $-(\mathrm{d} \theta / \mathrm{d} \sigma)-\sigma$ curves for B1, B2, and B3 steels at $0.1 \mathrm{~s}^{-1}$ and various deformation temperatures, as plotted in Fig. 3 . Consequently, the corresponding values of critical strain are obtained based on the true stress-strain data. Accordingly, the critical strain is precisely measured to be 0.10 , $0.10,0.10,0.14$, and 0.15 for steel B1 and $0.15,0.13,0.15$, 0.14 , and 0.14 for steel B3 at 1100, 1050, 1000, 950, and $900{ }^{\circ} \mathrm{C}$, respectively. In conclusion, the $\theta-\sigma$ and $-(\mathrm{d} \theta / \mathrm{d} \sigma)-\sigma$ curves are utilized to extract the peak and critical stresses and strains for all ranges of analyzed deformation and temperature conditions. 

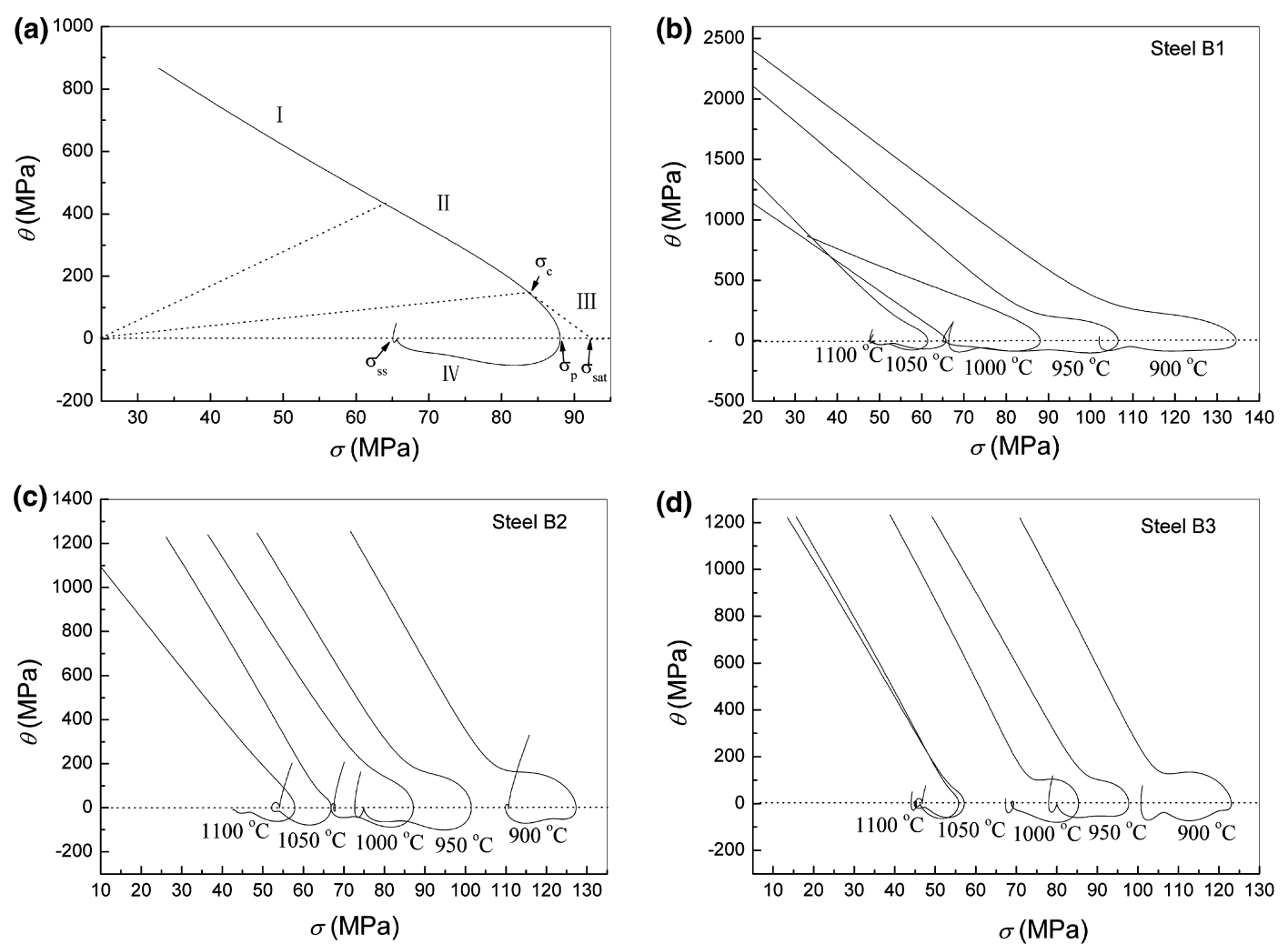

Fig. 2 Typical curve of $\theta-\sigma$ showing the four phases dividing $\mathbf{a}$, and the plots of $\theta-\sigma$ at $0.1 \mathrm{~s}^{-1}$ and different temperatures for steel B1 b, steel B2 c, steel B3 d
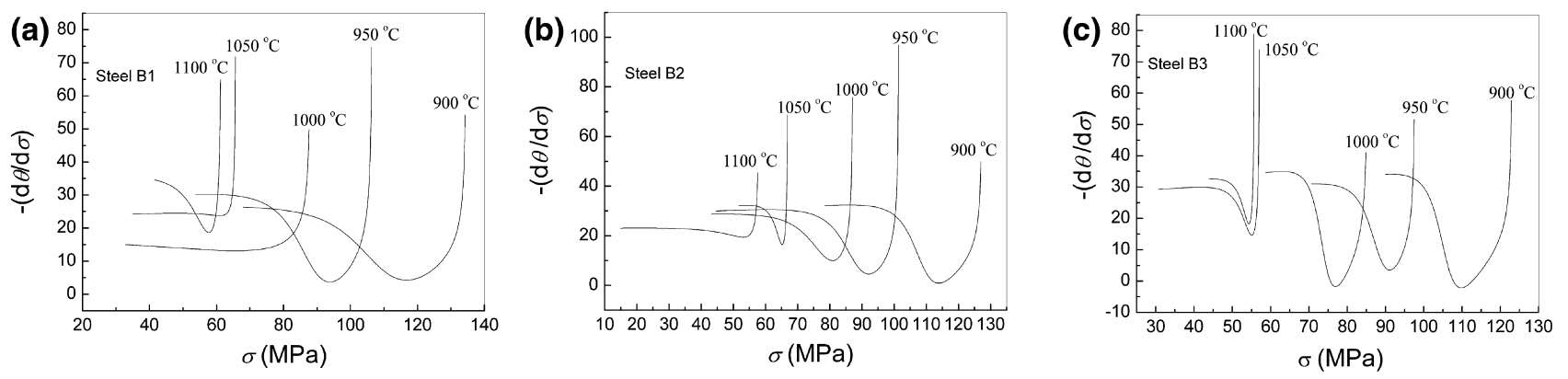

Fig. 3 Curves of $-(\mathrm{d} \theta / \mathrm{d} \sigma)-\sigma$ at strain rate $0.1 \mathrm{~s}^{-1}$ and different temperatures: a steel B1, b steel B2, c steel B3

\subsection{Analysis of DRX Behaviors}

\subsubsection{Effect of Boron on Critical DRX Parameters}

To perform a detailed study of the effect of boron content on the DRX behavior, the peak and critical stresses and strains are analyzed. In Fig. 4, the peak and critical stresses and strains at $0.1 \mathrm{~s}^{-1}$ are plotted as a function of deformation temperature. As seen in the plot, peak and critical stresses increase with decreasing boron concentration and temperature, proving that steel B3 is softer than steel B1 at high temperatures, as previously mentioned; therefore, it is evident that the addition of boron produces softening and retards DRX of the steel at high temperature conditions, while noting that peak and critical strains increase with the addition of boron as well. It is worth mentioning that some curves show deviation from theoretical values associated with experimental error and the noise level of the experimental data. These obtained results are in good agreement with the experimental results reported by Banks et al. [19] and Kim et al. [18], who also found that boron delayed the onset and rate of DRX. Additionally, Hondros and Seah [12] and Wang and He [35] indicated that boron segregation to austenite grain boundaries retards mobility and recrystallisation kinetics during hot working, which retards dynamic recrystallization when solute molecules drag by boron located on austenite grain boundaries. 

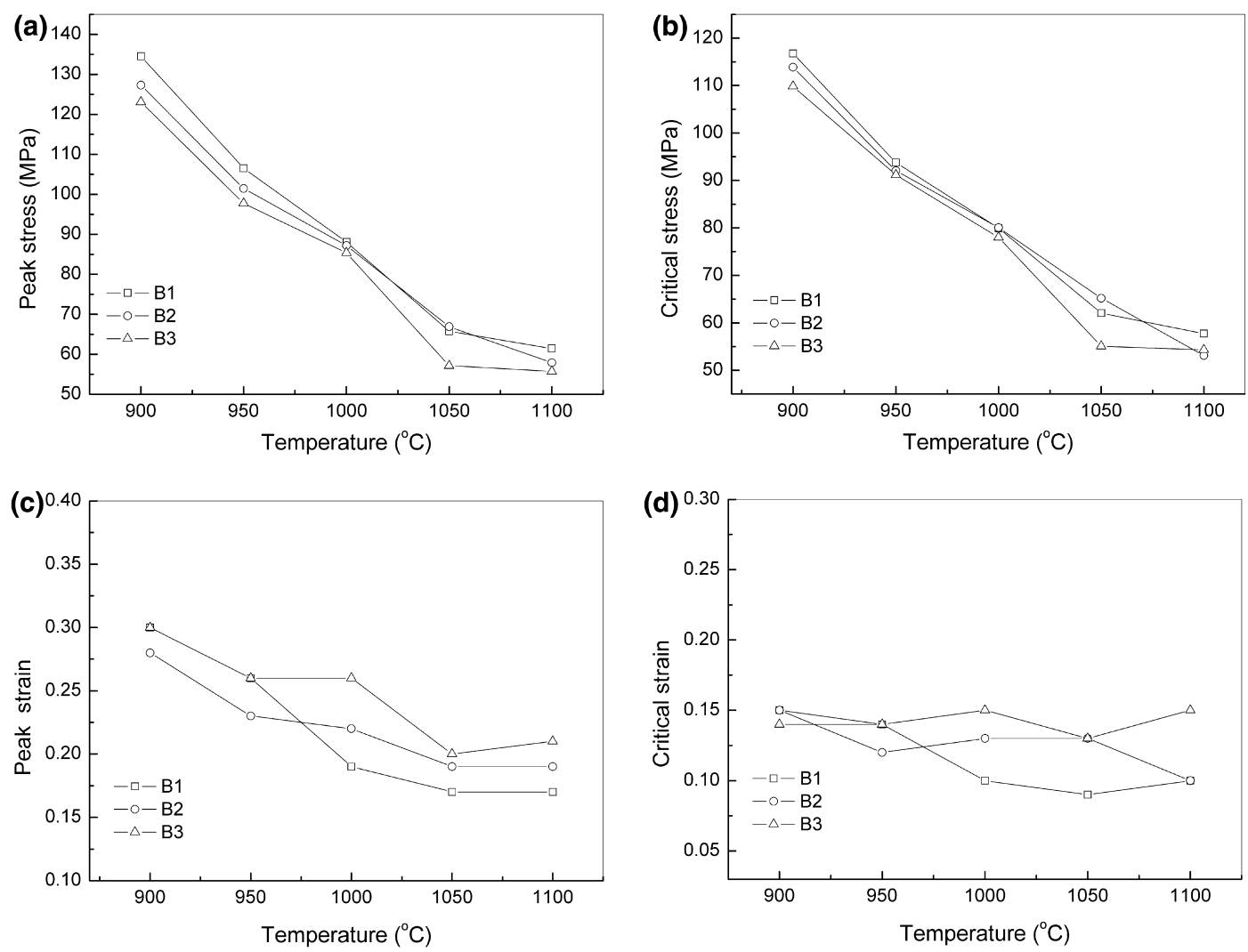

Fig. 4 Critical DRX parameters versus temperature at $0.1 \mathrm{~s}^{-1}$ : a peak stress, $\mathbf{b}$ critical stress, $\mathbf{c}$ peak strain, $\mathbf{d}$ critical strain

Peak and critical stresses are observed to decrease with increasing boron content at a strain rate of $1 \mathrm{~s}^{-1}$, shown in Fig. 5, owing to the importance of the effect of softening of boron on DRX mechanism at different strains. It is imperative to note that peak and critical strain has a negligible change with increasing boron content at different temperatures except at $1100{ }^{\circ} \mathrm{C}$. Such behavior is attributed to the faster deformation process that does not allow for additional boron to segregate at austenite grain boundaries. Additionally, the deformation energy per unit time and the amount of available nucleation sites increase by improving strain rate; thus, the driving force is significantly enhanced and becomes the primary contributing factor for the occurrence of DRX.

Based on the analysis of characteristic points, it can be obtained that the mean critical stress ratio $\left(\sigma_{\mathrm{c}} / \sigma_{\mathrm{p}}\right)$ and the mean critical strain ratio $\left(\varepsilon_{\mathrm{c}} / \varepsilon_{\mathrm{p}}\right)$ are 0.92 and 0.55 , respectively. In this case, the critical stress ratio is higher than the literature value of $0.800[25,36]$, yet the critical strain ratio is in agreement with those values reported in the range of 0.500 and $0.600[25,37]$.

\subsubsection{Effect of Boron on Initial Austenite Grain}

The aforementioned results clearly show a strong function of boron on hot deformation and its retardation of the onset of
DRX. In addition, the initial austenite grain size has also been shown to have an effect on the DRX behavior. The relationship between peak strain $\left(\varepsilon_{\mathrm{p}}\right)$ and initial austenite grain size $\left(d_{0}\right)$ was proven where the following equation was given: $\varepsilon_{\mathrm{p}}=A d_{0}^{\mathrm{m}} Z^{\mathrm{p}}$, where $m$ and $p$ are coefficients determined for a specific material [23]. As aforementioned, the critical strain is related to the peak strain by the following relationship: $\varepsilon_{\mathrm{c}}=0.55 \varepsilon_{\mathrm{p}}$. By combining equations, critical strain is found to increase with increasing initial austenite grain size.

In order to perform a more detailed investigation of boron concentration on DRX behavior, the initial austenite grain sizes of steels with different boron content were examined. Figure 6 shows the microstructures of steel samples that demonstrate the initial grain size incrementally increases with the addition of boron. The initial austenite grain size was measured as approximately 83,105 , and $138 \mu \mathrm{m}$ for steels B1, B2, and B3, respectively, using the linear intercept method, with a standard deviation of 2.13, 3.94, and 3.77. This trend can be attributed to the fact that the amount of fine AlN reduces because of the formation of BN. Zhang et al. [38] have reported that AlN can pin the austenite grain boundaries and retard the growth of austenite grain. BN can be produced earlier than AlN at an identical temperature, as shown in Fig. 7 [39]. Li et al. [40] observed a different content of AlN present in boron-free and boron-treated steel, 

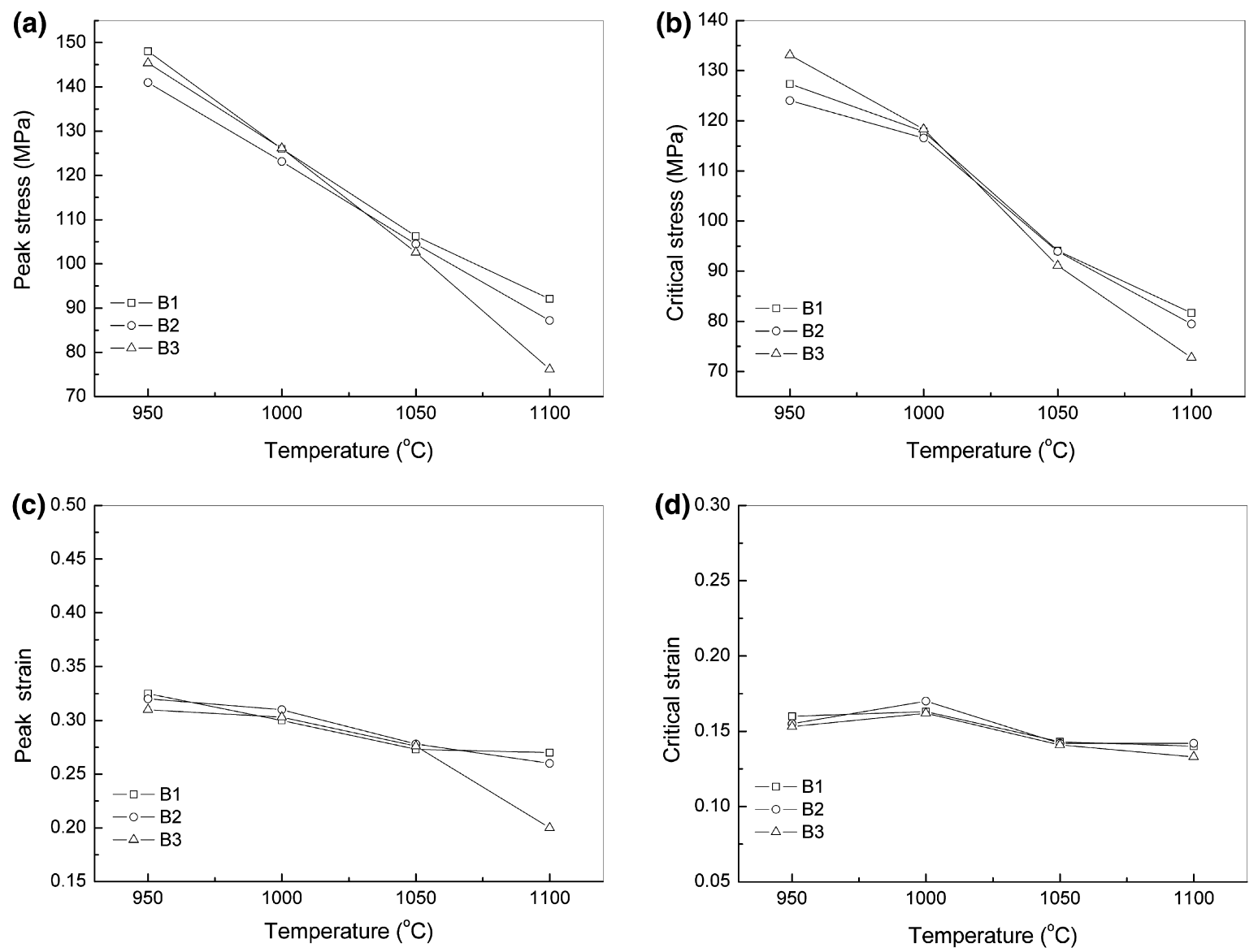

Fig. 5 Critical DRX parameters versus temperature at $1 \mathrm{~s}^{-1}$ : a peak stress, b critical stress, $\mathbf{c}$ peak strain, $\mathbf{d}$ critical strain
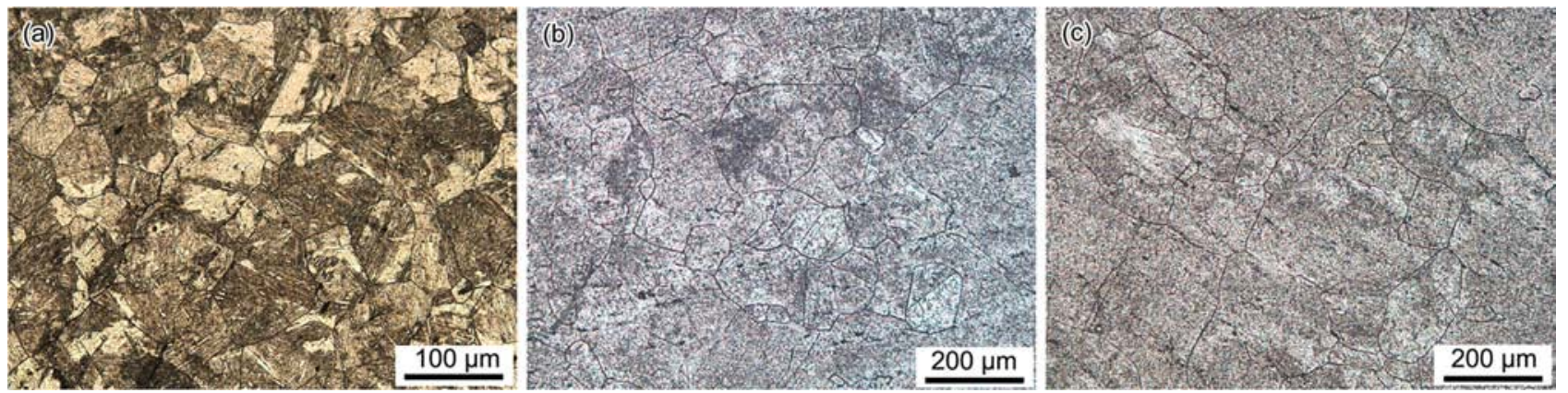

Fig. 6 Austenite grain size of the specimens at austenitizing temperature of $1150{ }^{\circ} \mathrm{C}$ : a steel B1, b steel B2, c steel B3

with expected results showing the amount of AlN decreases in boron-treated steel.

In addition, Fernández et al. [23] indicated that initial austenite grain size has little influence on peak stress; therefore, boron addition can delay the onset of DRX in hot working.

\subsubsection{Kinetics Model of DRX}

The DRX evolution of the deformed steel primarily depends on the density and distribution of dislocation during the deformation process. During hot deformation process, dislocations continually increase and accumulate to a great extent, in which the DRX nucleus would form and accumulate near grain boundaries, twin boundaries, and deformation bands. It is generally accepted that the conflicting effects coexist between the multiplication of dislocation due to continual hot deformation and the annihilation of dislocation due to DRX. When a dynamic balance is formed by work hardening corresponding to the former and DRX softening corresponding to the latter, flow stress will remain 


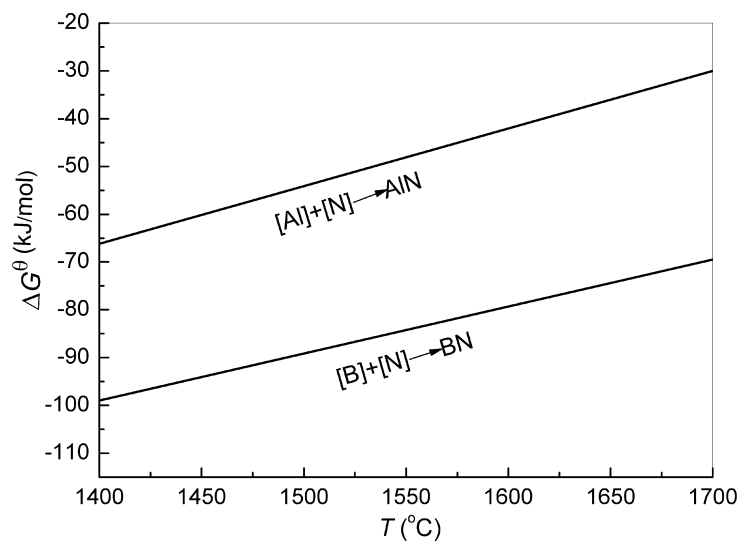

Fig. $7 \Delta G^{\theta}$ of producing $\mathrm{AlN}$ and $\mathrm{BN}$ at different temperatures

constant with increasing strain. Meanwhile, deformation reaches a steady state in which complete DRX grains have equiaxed shape and hold a constant size [41]. When such dynamic balance is upset, flow stress continuously increases or decreases. The kinetics of DRX can be described in terms of normal $\mathrm{S}$ curves of the recrystallized volume expressed as a function of time, similar to those observed in classical recrystallization phenomenon. At constant strain rates, time can be replaced by strain, and the recrystallized fraction can be described by the modified Avrami equation [42].

In this study, kinetics of DRX is proposed as follows: [43]

$X_{\mathrm{d}}=1-\exp \left[-k\left(\left(\varepsilon-\varepsilon_{\mathrm{c}}\right) / \varepsilon_{\mathrm{p}}\right)^{n}\right]$,

where $X_{\mathrm{d}}$ is the DRX fraction, $k$ and $n$ are the Avrami's constants, $\varepsilon, \varepsilon_{\mathrm{c}}$, and $\varepsilon_{\mathrm{p}}$ are the true strain, the critical strain, and the peak strain, respectively. In general, it is hard to determine the recrystallized fraction $X_{\mathrm{d}}$ under different deformation conditions by the sole analysis of microstructural properties. However, the true stress-strain curves with DRX characteristics provided valuable information pertaining to $X_{\mathrm{d}}$. In order to determine the progress of dynamic recrystallization fraction, the following expression is employed [44]:

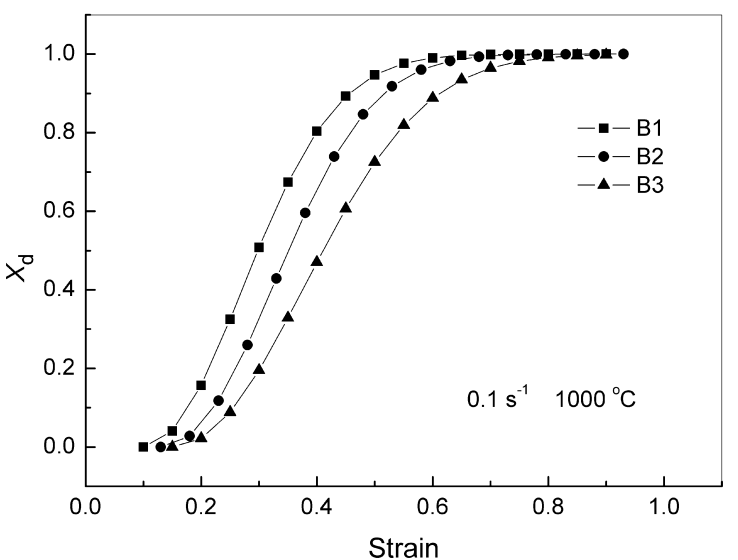

Fig. 9 Predicted volume fractions of dynamic recrystallization at temperature $1000{ }^{\circ} \mathrm{C}$ and strain rate $0.1 \mathrm{~s}^{-1}$

$X_{\mathrm{d}}=\left(\sigma_{\mathrm{sat}}^{2}-\sigma^{2}\right) /\left(\sigma_{\mathrm{sat}}^{2}-\sigma_{\mathrm{ss}}^{2}\right)$,

where $\sigma$ is instantaneous stress at different strain, and $\sigma_{\text {sat }}$ and $\sigma_{\mathrm{ss}}$ are saturated stress and steady stress for DRX, respectively, and are determined according to Fig. 3. Combining Eqs. (1) and (2), as shown in Fig. 8, a linear relationship between $\ln \left[-\ln \left(1-X_{\mathrm{d}}\right)\right]$ and $\ln \left[\left(\varepsilon-\varepsilon_{\mathrm{c}}\right) / \varepsilon_{\mathrm{p}}\right]$ under different deformation conditions is observed. By means of linear regression analysis, the average values of $k$ and $n$ were calculated. Therefore, the resulting equations for $X_{\mathrm{d}}$ of tested steels are given as follows:

$X_{\mathrm{d}(\mathrm{B} 1)}=1-\exp \left[-0.63789\left(\left(\varepsilon-\varepsilon_{\mathrm{c}}\right) / \varepsilon_{\mathrm{p}}\right)^{2.0534}\right]$,

$X_{\mathrm{d}(\mathrm{B} 2)}=1-\exp \left[-0.68765\left(\left(\varepsilon-\varepsilon_{\mathrm{c}}\right) / \varepsilon_{\mathrm{p}}\right)^{2.1606}\right]$,

$X_{\mathrm{d}(\mathrm{B} 3)}=1-\exp \left[-0.69048\left(\left(\varepsilon-\varepsilon_{\mathrm{c}}\right) / \varepsilon_{\mathrm{p}}\right)^{2.1047}\right]$.

The effects of boron content on the DRX volume fraction are displayed in Fig. 9 showing all the curves exhibiting a ' $S$ ' shape. To explain, the DRX volume fraction increases slowly with an increase in strain at the beginning of deformation, markedly in the middle, and then slowly near the end of deformation. Furthermore, the DRX volume


Fig. $8 \ln \left[-\ln \left(1-X_{\mathrm{d}}\right)\right]$ versus $\ln \left[\left(\varepsilon-\varepsilon_{\mathrm{c}}\right) / \varepsilon_{\mathrm{p}}\right]$ under different deformation conditions: a steel B1, b steel B2, c steel B3 
fraction diminishes with an increase of boron content, indicating that the addition of boron causes a delay of DRX kinetics during hot deformation. The aforementioned obtained result is in good agreement with the experimental result of Mejía et al. [45].

\section{Conclusions}

1. Hot flow curves of boron-treated steels demonstrate a classification into two types, dynamic recovery at a strain rate of $10 \mathrm{~s}^{-1}$ and dynamic recrystallization at strain rates 0.1 and $1 \mathrm{~s}^{-1}$. In the dynamic recrystallization process, peak stresses tend to decrease as boron content increases. In the dynamic recovery process, boron-treated steel $(0.004 \mathrm{wt} \%)$ displays a higher flow resistance than others $(0.002$ and $0.006 \mathrm{wt} \%)$.

2. Both peak and critical stresses tend to decrease as boron content increases, indicating boron facilitating a softening effect due to its non-equilibrium segregation. Peak and critical strains increase as boron content increased, indicating that boron addition can delay the onset of dynamic recrystallization.

3. The initial austenite grain size of steel proves to be larger in more boron-rich steels at $1150{ }^{\circ} \mathrm{C}$. The result shows that boron addition can delay the onset of dynamic recrystallization.

4. The kinetics models of dynamic recrystallization for three boron-treated steels were established, which indicated that the addition of boron causes a delay of the dynamic recrystallization kinetics during hot deformation.

Acknowledgments This work was financially supported by the National Science Foundation of China (No. 51374052), Basic Research of Key Laboratory of Education Department of Liaoning (No. LZ2014-022), and the Century Excellent Talent in University (No. NCET-11-0074).

\section{References}

[1] Y. Wang, Q.L. Pan, Y.F. Song, C. Li, Z.F. Li, Mater. Des. 51, $160(2013)$

[2] G. Xu, L.N. Wang, S.Q. Li, L. Wang, Acta Metall. Sin. (Engl. Lett.) 25, 382 (2012)

[3] I. Salvatori, T. Inoue, K. Nagai, ISIJ Int. 42, 750 (2002)

[4] X.L. Gao, M.Y. Zhu, C. Sun, G.Q. Fu, Steel Res. Int. 84, 386 (2013)

[5] M.H. Wang, W.H. Wang, J.J. Dong, L.H. Zhang, Y.P. Li, A. Chiba, Acta Metall. Sin. (Engl. Lett.) 25, 434 (2012)
[6] T. Schambron, L. Chen, T. Gooch, A.D. Manshadi, E.V. Pereloma, Steel Res. Int. 84, 1195 (2013)

[7] L.Y. Lan, C.L. Qiu, P. Zhou, D.W. Zhao, C.M. Li, X.H. Gao, L.X. Du, Acta Metall. Sin. (Engl. Lett.) 24, 486 (2011)

[8] Y.S. Choi, S.J. Kim, I.M. Park, K.W. Kwon, I.S. Yoo, Met. Mater. Int. 3, 124 (1997)

[9] I. Mejía, A.B. Jacuinde, C. Maldonado, J.M. Cabrera, Mater. Sci. Eng. A 528, 4474 (2011)

[10] T.D. Xu, S. Song, Z. Yuan, Z. Yu, J. Mater. Sci. 25, 1744 (1990)

[11] M. Chapman, R. Faulkner, Acta Metall. 31, 689 (1983)

[12] E.D. Hondros, M.P. Seah, Int. Met. Rev. 22, 301 (1977)

[13] I. Mejía, A.B. Jacuinde, C. Maldonado, J.M. Cabrera, Mater. Sci. Eng. A 528, 4140 (2011)

[14] E.L. Chipres, I. Mejía, C. Maldonado, A.B. Jacuinde, M.E. Wahabi, J.M. Cabrera, Mater. Sci. Eng. A 480, 55 (2008)

[15] E.M. Schulson, T.P. Weihs, I. Baker, H.J. Frost, J.A. Horton, Acta Metall. 34, 1399 (1985)

[16] E.M. Schulson, T.P. Weihs, D.V. Viens, I. Baker, Acta Metall. 33, 1591 (1985)

[17] I. Baker, E.M. Schulson, Philos. Mag. 57, 385 (1988)

[18] S.I. Kim, S.H. Choi, Y. Leec, Mater. Sci. Eng. A 406, 133 (2005)

[19] K. Banks, W. Stumpf, A. Tuling, Mater. Sci. Eng. A 421, 316 (2006)

[20] W. Stumpf, K. Banks, Mater. Sci. Eng. A 418, 94 (2006)

[21] J.P. Sah, G.J. Richardson, C.M. Sellars, Met. Sci. 8, 331 (1974)

[22] W. Roberts, H. Bodén, B. Ahlblom, Met. Sci. 13, 205 (1979)

[23] A.I. Fernández, P. Uranga, B. López, J.M. Rodriguez-Ibabe, Mater. Sci. Eng. A 361, 376 (2003)

[24] E.I. Poliak, J.J. Jonas, Acta Mater. 44, 136 (1996)

[25] E.I. Poliak, J.J. Jonas, ISIJ Int. 43, 691 (2003)

[26] H.L. Wei, G.Q. Liu, Mater. Des. 56, 444 (2014)

[27] W.J. Arnoult, R.B. McLellan, Acta Metall. 23, 56 (1975)

[28] M. Jahazi, J.J. Jonas, Mater. Sci. Eng. A 335, 61 (2002)

[29] B.V. Petukhov, Crystallogr. Rep. 52, 122 (2007)

[30] K. Okazaki, J. Mater. Sci. 31, 1099 (1996)

[31] K.T. Aust, R.E. Hanneman, P. Niessen, J.H. Westbrook, Acta Metall. 16, 302 (1968)

[32] A. Momeni, K. Dehghani, H. Keshmiri, G.R. Ebrahimi, Mater. Sci. Eng. A 527, 1611 (2010)

[33] Y.C. Lin, M.S. Chen, J. Zhong, Comput. Mater. Sci. 42, 477 (2008)

[34] G.Z. Quan, G.S. Li, T. Chen, Y.X. Wang, Y.W. Zhang, J. Zhou, Mater. Sci. Eng. A 528, 4651 (2011)

[35] X. Wang, X.L. He, ISIJ Int. 42, 46 (2002)

[36] M. Shaban, B. Eghbali, Mater. Sci. Eng. A 527, 4325 (2010)

[37] M.H. Mirzadeh, A. Najafizadeh, Mater. Des. 31, 1179 (2010)

[38] T. Zhang, X.M. Zhang, Z.Y. Guo, Y.Q. Wang, C.G. Li, L.Y. Lan, Acta Metall. Sin. (Engl. Lett.) 26, 488 (2013)

[39] Y.J. Liang, Y.C. Che, Thermodynamics Date of Inorganic Matter (Northeastern University Press, Shenyang, 1993). (in Chinese)

[40] P.S. Li, L.J. Xiao, Z. Xie, J. Iron. Steel. Res. 21, 21 (2009)

[41] G.L. Ji, F.G. Li, Q.H. Li, H.Q. Li, Z. Li, Mater. Sci. Eng. A 527, $2355(2010)$

[42] S.F. Medina, C.A. Hernandez, Acta Mater. 44, 149 (1996)

[43] L.X. Kong, P.D. Hodgson, B. Wang, J. Mater. Process. Technol. 89, 50 (1999)

[44] H.Z. Li, H.J. Wang, Z. Li, C.M. Liu, H.T. Liu, Mater. Sci. Eng. A 528, 160 (2010)

[45] I. Mejía, E.L. Chipres, C. Maldonado, A.B. Jacuinde, J.M. Cabrera, Int. J. Mater. Res. 99, 1345 (2008) 